\title{
KERAGAAN AGROINDUSTRI KOPI BUBUK (Studi Kasus pada Agroindustri Kopi Selangit di Kabupaten Musi Rawas)
}

\author{
Nenny Wahyuni \\ Dosen pada Prodi Agribisnis Universitas Musi Rawas \\ Email: nennywahyuni@ymail.com
}

\begin{abstract}
Coffee plant at Selangit Regency is unique, coffee was plant under rubber plant between durian plant. The existence of coffee plant has bring up industry of coffee powder since 2007. In 2013 coffee powder industry get attention from MusiRawas Regency government under founding of KPH MusiRawas and release prime product of coffee with brand "Kopi Selangit". The purpose of this research was to identifird performance of coffe powder industry and analize the benefit of Kopi Selangit industry at MusiRawas Regency. The research method used was case study, with respondencechoosen purposively.

The result of this study shows that production of coffee powder has variative measurement and packaging. The production of Kopi Selangit as much as $140 \mathrm{~kg}$ per month or $1.680 \mathrm{~kg}$ per year. Benefit from this production as much as Rp. 4.696.487 per month with 5 times production, and this industry categorize as capital intensive industry.
\end{abstract}

Key Word: Industry, Coffee Powder,Performace

\begin{abstract}
Abstrak
Perkebunan kopi di Kecamatan Selangit memiliki keunikan tersendiri, dimana tanaman kopi ditanam di bawah batang pohon karet dan di antara pohon durian. Hasil panen perkebunan kopi di Kecamatan Selangit ini memunculkan industri pengolahan kopi bubuk yang mulai beroperasi Tahun 2007. Pada tahun 2013 industri ini mendapat perhatian pemerintah Kabupaten Musi Rawas dan berkembang dibawah binaan Kesatuan Pengelolaan Hutan (KPH) Musi Rawas hingga hadir produk kopi unggulan daerah yang diberi brand Kopi Selangit.

Tujuan dari penelitian ini adalah untuk mengidentifikasi keragaan industry pengolahan kopi bubuk, dan menganalisa keuntungan usaha Kopi Bubuk Selangit yang ada di Kabupaten Musi Rawas. Metode penelitian yang digunakan adalah metode studi kasus, sedangkana penentuan responden dilakukan secara sengaja (purposive)

Hasil penelitian menunjukkan bahwa, kopi bubuk di produksi dalam bermacam ukuran dan varian kemasan. Produk yang dihasilkan sebanyak $140 \mathrm{~kg}$ kopi bubuk perbulannya atau $1.680 \mathrm{~kg}$ per tahunnya. Keuntungan yang diterima usaha pengolahan yaitu sebesar Rp. 4.696.487 per bulan setelah melalui lima kali proses produksi. Oleh karena itu usaha pengolahan kopi ini digolongkan dalam katagori usaha padat modal
\end{abstract}

Kata Kunci: Industry, Keragaan, Kopi bubuk

Jurnal AGRIBIS Vol 14. No. 1 Januari 2021 Hal 1659-1668 


\section{BAB 1. PENDAHULUAN}

\subsection{Latar Belakang}

Agribisnis perkebunan memegang peranan penting dalam perkembangan perekonomian di Indonesia. Sektor perkebunan ini menyediakan lebih dari 19,4 juta lapangan kerja bagi penduduk Indonesia, selain itu sektor perkebunan juga menambah devisa Negara secara signifikan (Rahardjo, Puji. 2012). Komoditas kopi merupakan salah satu komoditas penting dalam subsektor perkebunan. Penyumbang kopi terbesar adalah Sumatera (Saragih, 2007).Sumatera Selatan menjadi provinsi penghasil kopi terbesar di Indonesia dengan luas areal perkebuan kopi 249.710 hektar dan produksi sebesar 110.380 ton pada tahun 2016. Kabupaten Musi Rawas sebagai bagian dari Provinsi Sumatera Selatan memiliki lahan perkebunan kopi seluas 3.738 hektar dengan produksi 2.585 ton pada tahun 2017. Perkebunan kopi ini tersebar di beberapa kecamatan, salah satunya adalah perkebunan kopi yang berada di Kecamatan Selangit Kabupaten Musi Rawas (Badan Pusat Statitik, 2018).
Perkebunan kopi di Kecamatan Selangit memiliki keunikan tersendiri, dimana tanaman kopi ditanam di bawah batang pohon karet dan di antara pohon durian. Penanaman ini dilakukan dalam rangka mencegah terjadinya penebangan hutan liar atau penggundulan hutan yang sering dilakukan oleh masyarakat desa sehingga kelestarian lingkungan hutan di sekitar desa bisa terjaga.

Hasil panen perkebunan kopi di Kecamatan Selangit ini memunculkan industri pengolahan kopi bubuk yang mulai beroperasi Tahun 2007. Pada tahun 2013 industri ini mendapat perhatian pemerintah Kabupaten Musi Rawas dan berkembang dibawah binaan Kesatuan Pengelolaan Hutan (KPH) Musi Rawas hingga hadir produk kopi unggulan daerah yang diberi brand Kopi Selangit.Dalam rangka mengidentifikasi potensi pengembangan industri kopi bubuk di Kabupaten Musi Rawas maka perlu diidentifikasi keuntungan usaha kopi bubuk pada Usaha Kopi Bubuk Selangit.

\subsection{Rumusan Masalah}

Permasalahan yang menarik untuk diteliti adalahberapa keuntungan usaha 
Kopi Bubuk Selangit di Kabupaten Musi Rawas.

\subsection{Tujuan Penelitian}

Penelitian ini bertujuan untuk menghitung keuntungan usaha Kopi Bubuk Selangit di Kabupaten Musi Rawas.

BAB2. METODOLOGI PENELITIAN

Penelitian ini dilaksanakan di Kecamatan Selangit Kabupaten Musi Rawas pada Tahun 2018.Metode penelitian yang digunakan adalah metode studi kasus. Penentuan responden dilakukan secara sengaja (purposive), dan data yang dikumpulkan dalam penelitian ini berupa data primer dan data sekunder. Data primer berasal dari hasil wawancara responden yang dilakukan dengan panduan kuisioner. Sedangkan data sekunder diperoleh dari dinas dan instansi terkait di Kabupaten Musi Rawas.

Untuk menghitung keuntungan usaha dapat menggunakan rumus sebagai berikut (Ahmadi, 2005):

$\pi=\mathrm{TR}-\mathrm{TC}$

Selain itu untuk mengukur tingkat keuntungan juga perlu dihitung R/C Ratio dengan rumus sebagai berikut (Suratiyah, 2015):

$\mathrm{R} / \mathrm{C}$ rasio $=\frac{T R}{T C} \times 100 \%$

Keterangan :

$\pi$ : KeuntunganUsahaPengolahan

Kopi

TR : Total Penerimaan Usaha

TC : Total Biaya Produksi Usaha

Seluruh data akan ditabulasi untuk selanjutnya diolah secara matematis dan hasilnya akan dijelaskan secara deskriptif.

BAB 3. HASIL DAN PEMBAHASAN

3.1. KarakteristikIndustriPengolahan Kopi Selangit

Industri pengolahan kopi bubuk ini berdiri pada tahun 2013 denganstatus kepemilikan perorangan karena modal yang dipakai dalam usaha kopi bubuk ini adalah sepenuhnya modal milik sendiri.Namundalampengelolaanya usaha ini tak terlepas dari binaan $\mathrm{KPPH}$ dan Pemerintahan Kabupaten Musi Rawas.

Usaha pengolahan kopi ini diawalijasa penggilingan kopi pada tahun 2007. Keberadaanbahan baku yang cukup memadai dan adanya peluang usaha memunculkan inisiatif untuk mulai mendirikan industri kopi bubuk dengan logo kopi bubuk selangit pada Tahun 
2013. Usaha ini dikelola dengan modal sendiri, modal ini digunakan untuk pembelian bahan produksi yaitu beras kopi, wajan, sotel, kayu bakar, baskom kopi, packing kopi. dan modal untuk biaya operasional lainnya.

Kegiatan utama usahainiadalah memproduksi beras kopi dan menjualnya dalam bentuk produk utama yaitu kopi bubuk hitam asli. Alur produksi pada Pengolahan Kopi Bubuk diawali dengan mendatangkan biji kopi pilihan kemudian melakukan penyortiran yang berlangsung selama kurang lebih 3 jam yang dilakukan oleh 2 orang, yang kemudian dilanjutkan dengan penyangraian yang dilakukan kurang lebih selama 3 jam dengan 2 orang tenaga kerja, kemudian kopi yang sudah disangrai di proses lebih lanjut yaitu dengan melakukan penggilingan yg dilakukan oleh 1 orang selama 2 jam, dan kemudian sesudah penggilingan yaitu ke tahap pengemasan (packing) yang dilakukan 3 orang juga dan memakan waktu kurang lebih selama 2 jam, setelah itu barulah Kopi Bubuk Selangit siap untuk dipasarkan.

Produk yang dihasilkan berupa produk utama. Produk utama yang dihasilkan yaitu kopi bubuk hitam asli/original kemasan 200gr dan Kopi buah petik merah kemasan 100 gr (Gambar 1). Kopi bubuk dijual per kemasan (pcs) dengan berat yang berbeda yaitu 200 gram dijual dengan harga Rp.20.000 dan kemudian kemasan 100 gram dijual dengan harga Rp.10.000.

Pendistribusian produk ke pelanggan dilakukan melalui dua alternatif. Alternatif pertama pengolahan mengantarkan produk ke pelanggan seperti ke barista coffe dan beberapa hotel di lubuk linggau, alternatif kedua pelanggan yang mengambil kopi langsung di tempat pengolahan. Kegiatan promosi dilakukan melalui menawarkan produk langsung ke pelanggan, seperti mendirikan stand kopi di tempat pameran dan perhelatan-perhelatan besar. pelanggan yang ditargetkan yaitu pedagang besar seperti industri telur asin. Kegiatan promosi juga dapat dilakukan melalui bantuan dari para pengolahan kopi lain misalnya saling berbagi informasi diantara para pengelola kopi mengenai tempat dimana akan diadakannya pameran selanjutnya, hargaharga hasil produksi usaha pengolahan kopi bubuk, peluang pasar, dan lain-lain. 


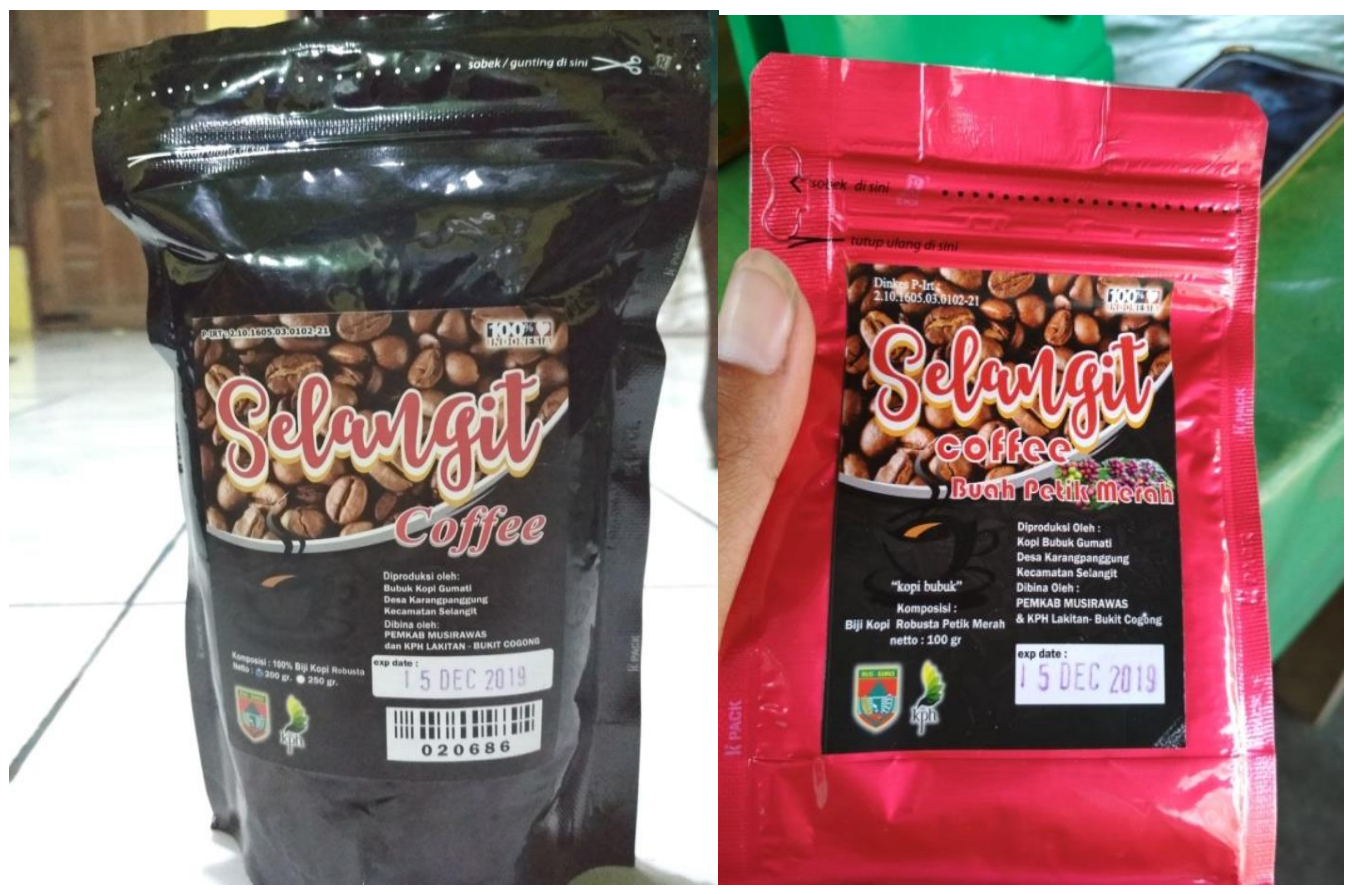

Gambar 1. Produk Kopi Selangit

\subsection{Penggunaan Peralatan}

Perencanaan pengadaan peralatan dari bahan baku yang efektif dan efisien dapat menjadikan kegiatan produksi berjalan lancar dan dapat meningkatkan hasil dan keuntungan bagi usaha pengolahan Kopi Selangit.

Total biaya peralatan yang dikeluarkandalam pengolahan kopi bubuk selangit, adalah Rp. 12.380.000. Biaya peralatan yang terbesar untuk pembelian mesin diesel penggerak gerinder (gambar2) Rp. 4.500.000. dan biaya terendah yang dikeluarkan untuk pembelian spatula seharga Rp. 15.000. per unitnya. Secara biaya terbesar ke dua adalah pembelian mesin power pack (gambar 3) seharga Rp. 3.700.000. Biaya keseluruhan nilai penyusutan peralatan sebesar Rp. 174.942. per bulannya, dan biaya pertahunnya sebesar Rp. 2.107.857.

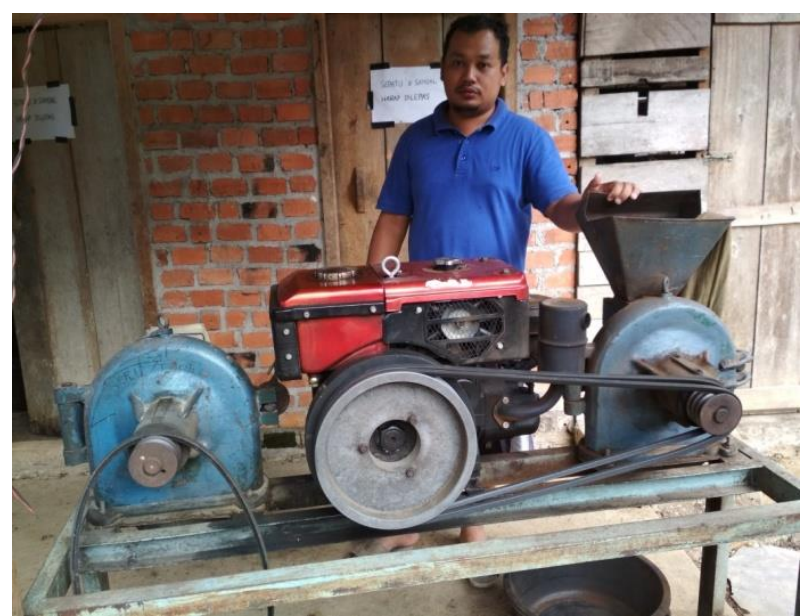

Gambar 2 


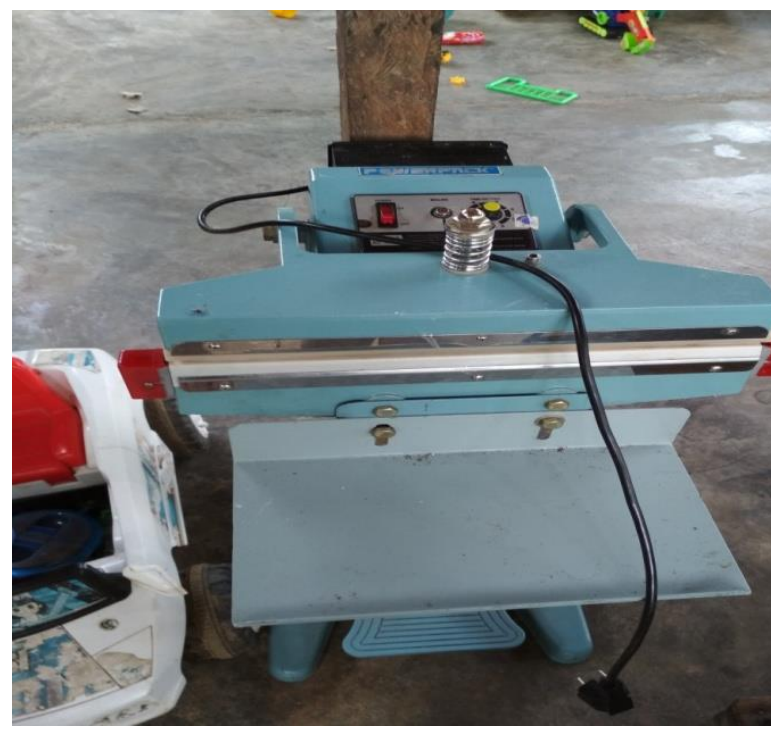

Gambar 3

\subsection{Penyediaan Bahan Baku}

Bahan baku merupakan bahan mentah yang diolah dan dapat dimanfaatkan sebagai sarana produksi dalam suatu pengolahan atau agroindustri. Ketersediaan bahan baku secara cukup dan berkelanjutan akan menjamin suatu kegiatan usaha untuk bisa berproduksi dalam waktu yang relatif lama. Dalam melakukan pengolahan kopi bubuk organik, bahan baku utama yang digunakan adalah kopi beras, sedangkan bahan baku penolong lain yang digunakan adalah kayu bakar, dan solar. Ketersedian bahan baku yang ada cukup banyak, hal ini dikarenakan masyarakat di Kecamatan Selangit banyak yang membudidayakan tanaman kopi, Bahan baku dan bahan penolong dapat diperoleh dengan mudah karena ketersediaan maupun harga yang terjangkau sehinggga tidak menjadi suatu hambatan bagi usaha pengolahan kopi ini.

Bahan baku yang terbesar digunakan dalam satu kali proses produksi kopi bubuk adalah untuk pembelian bahan baku utama yaitu sebesar Rp.1.250.000. Sedangkan biaya terendah yang dikeluarkan yaitu untuk pembelian Bahan baku penolong (Solar) sebesar Rp.26.000. Dan jumlah biaya bahan penunjang (packing) yang dikeluarkan sebesar Rp.324.000. Dengan total keseluruhan biaya bahan baku yang digunakan untuk pengolahan kopi bubuk selangit adalah sebesar Rp.1.640.000. dan dalam satu bulan kopi bubuk selangit ber produksi sebanyak lima kali produksi yang artinya dalam satu bulan diperlukan biaya sebesar Rp. 8.200.000 untuk pengaadan bahan baku saja.

Tenaga kerja yang dibutuhkan dalam pengolahan kopi bubuk Selangit ini adalah sebanyak 5 orang tenaga kerja. Kelima tenaga kerja tersebut adalah lakilaki 2 orang dan perempuan 3 orang dengan upah Rp. 65.000 per orang dalam satu harinya/per produksinya. Tenaga 
kerja tersebut tidak selalu bekerja bersamadalam satu waktu. Masingmasing mempunyai tugas yang berbedabeda. Dalamsatu bulan dapat dilakukan proses produksi secara keseluruhan yang mencakupsortasi, sangrai, gerinder/giling, dan pengemasan.

\subsection{Proses Pengolahan Kopi Bubuk}

Proses pengolahan kopi bubuk Selangit pada tempat penelitian yaitu melalui beberapa tahapan pengolahan kopi bubuk pada umumnya, yaitu persiapan bahan baku, penyangraian (roasting), pencampuran, pendinginan, penggilingan, dan pengemasan. Proses pengolahan kopi bubuk ini akan dijelaskan secara rinci sebagai berikut :

\subsubsection{Persiapan Bahan Baku}

Setiap kali produksi responden membutuhkan lebih kurang 50 kilogram stok biji kopi untuk berlangsungnya proses pengolahan kopi bubuk ini untuk dua atau tiga hari sebelumnya responden sudah menyiapkan stoknya dengan cara membeli biji kopi secara langsung pada petani kopi di Desa Karang Panggung dan kemudian melakukan penyimpanan biji kopi yang belum diolah dalam gudang.

\subsubsection{Penyangraian (Roasting)}

Sebelum di sangrai biji kopi di sortir terlebih dauhulu selama 3 jam untuk memilih biji kopi terbaik,kopi yang telah di sortir dan kering ini kemudian disangrai dengan cara memasukkannya ke dalam wajan berukuran besar yang telah dipanaskan di atas kayu bakar dan sambil di aduk selama lebih kurang 2,5 jam. Setelah disangrai biji kopi segera didinginkan di dalam bak pendingin, selama pendinginan biji kopi diaduk secara manual agar proses pendinginan lebih cepat dan merata, serta berfungsi untuk memisahkan sisa kulit ari yang terlepas dari biji kopi saat proses sangrai, selama proses ini terjadi penyusutan berat kopi yang diolah sebesar 44 persen.

\subsubsection{Penggilingan}

Biji kopi yang telah disangrai selama kurang lebih 3 jam siap digiling hingga menjadi menjadi bubuk, setelah digiling hingga halus kopi bubuk yang dihasilkan siap dikemas dan dipasarkan.

\subsubsection{Pengemasan}

Kopi bubuk yang di hasilkan memiliki bermacam-macam ukuran dan varian, yaitu ukuran 100 gram dan 200 gram dengan varian kopi bubuk hitam orignal, kopi bubuk biji merah, dan kopi 
luwak liar, Tahapan pengemasan dilakukan dengan bantuan mesin powerpack. Proses pengemasan dilakukan dalam tiga tahap, yaitu memasukan kopi bubuk ke dalam kemasan, menimbang kemasan, dan menutup kemasan (Laminating Kemasan).

\subsection{Saluran Pemasaran Kopi Bubuk}

\section{Selangit}

Kegiatan proses pemasaran kopi bubuk olahan tempat penelitian ini ditemukan dua saluran pemasaran, yaitu saluran pemasaran pertama dan saluran pemasaran kedua. Saluran pemasaran pertama adalah proses pemasaran kopi bubuk oleh produsen secara langsung ke konsumen yaitu dengan memasukan kopi selangit ke Hotel-hotel tertentu di lubuklinggau dan juga pada baristabarista kopi tertentu (ProdusenKonsumen), sedangkan Saluran pemasaran kedua adalah proses pemasaran kopi bubuk oleh produsen dengan cara di distribusikannnya pada tempat diadakannya event event tertentu dan juga memasarkannya secara online sehingga para konsumen dengan cukup mudah untuk memperoleh kopi selangit.

\subsection{Produksi dan Nilai Produksi Kopi} Bubuk

Produksi adalah segala kegiatan yang ditujukan untuk menciptakan suatu barang atau jasa atau menambahkan keragaman makanan atau barang dan jasa (Hernanto, 2007). Produksi merupakan pendapatan kotor dalam bentuk fisik dari suatu proses produksi. Sedangkan nilai produksi merupakan pendapatan kotor yang diperoleh dari hasil perkalian antara jumlah produk yang diahasilkan (output) dengan harga jual yang berlaku di pasaran (Soekartawi, 2011).

Hasil produksi usaha pengolahan dalam satu bulan yaitu sebanyak $140 \mathrm{~kg}$ kopi bubuk perbulannya dan $1.680 \mathrm{~kg}$ pertahunnya. Kopi mengalami penyusutan sebesar $44 \%$ hal ini dikarenakan adanya sebagian biji kopi yang tidak memenuhi kategori kopi pilihan saat penyortiran. Kopi bubuk dijual dengan harga Rp. 100.000. /kg nya, hasil produksi ini adalah produksi normal setiap bulannya, dan biasanya produksi akan meningkat jika mendapatatkan pesanan dari konsumen atau jika ada event-event tertentu. 


\subsection{Keuntungan Usaha}

Keuntungan usaha kopi bubuk diperoleh dengan mengurangkan penerimaan dari penjualan kopi bubuk dengan biaya produksi, sehingga dapat diketahui berapa besar keuntungan atau kerugian yang diperoleh dalam usaha pengolahan kopi bubuk dalam satu bulan. Penerimaan usaha pengolahan kopi bubuk dalam satu bulan sebesar Rp. 14.000.000 dengan total biaya sebesar Rp. 9.303.513 sehingga diperoleh pendapatan usaha/ keuntungan pengolahan kopi bubuk selangit yaitu sebesar Rp. 4.696.487.

Biaya pembelian bahan baku kopi bubuk merupakan komponen biaya terbesar dalam usaha pengolahan kopi bubuk yang kemudian diikuti oleh biaya pembelian kemasan kopi, Hal ini terlihat dari persentase di dalam tabel diatas sebesar $67 \%$ dari keseluruhan biaya yang dikeluarkan untuk proses produksi kopi bubuk. Tingkat upah tenaga kerja ditentukan pada tingkat upah yang berlaku, lama kerja dan jumlah hari kerja. Secara keseluran jumlah biaya yang harus dikeluarkan oleh agroindustri pengolahan kopi bubuk selangit adalah sebesar Rp. 9.303.513.
Dengan penggunaan bahan baku utama yaitu beras kopi sebanyak $250 \mathrm{~kg}$ maka agroindustri memperoleh nilai produksi pengolahan kopi bubuk sebesar Rp. 14.000.000. dan Keuntungan bersih yang diterima usaha pengolahan yaitu sebesar Rp. 4.696.487 dalam per lima kali produksi satu bulan. Usaha pengolahan ini termasuk katagori usaha padat modal, itu dibuktikan dengan biaya yang dikeluarkan mencapai $67 \%$ untuk pengadaan bahan baku kopi bubuk dalam lima kali proses produksi atau satu bulan produksi.

\section{BAB 4. KESIMPULAN DAN SARAN}

\subsection{Kesimpulan}

Hasil penelitian menunjukkan bahwa:

1. Kopi bubuk yang di produksi dalam bermacam varian dan ukuran kemasan.

2. Pemasaran kopi bubuk selangit melalui dua saluran pemasaran.

3. Produksi dalam usaha pengolahan kopi sebanyak $140 \mathrm{~kg}$ kopi bubuk per bulan nya atau $1.680 \mathrm{~kg}$ pertahunnya.

4. Keuntungan usaha pengolahan kopi bubuk sebesar Rp. 4.696.487 dari lima kali produksi per bulan. 
5. Usaha pengolahan ini termasuk katagori usaha padat modal.

\subsection{Saran}

Berdasarkan hasil penelitian ini maka peneliti menyarankan pelaku usaha kopi bubuk mengembangkan usaha pengolahan kopi dengan menyiapkan lebih banyak variasi kemasan sehingga lebih menarik. Sementara itu pemerintah daerah dapat membantu pemasaran agar produk unggulan usaha pengolahan kopi ini mampu bersaing.

\section{DAFTAR PUSTAKA}

Ahmadi. 2005. Ilmu Usahatani. Penebar Swadaya: Jakarta.
Badan Pusat Statistik. 2018. Musi Rawas dalam Angka. Muara Beliti.

Direkorat Jenderal Perkebunan. 2018. Statistika Perkebunan Indonesia. Jakarta.

Hernanto, F. 2007. Ilmu Usahatani. Penebar Swadaya: Jakarta.

Rahardjo, Pudji. 2012. Panduan Budidaya dan Pengolahan Kopi Arabika dan Robusta. Penebar Swadaya. Jakarta.

Saragih, I. Sartika, D. Iwan. 2007. Analisis Pendapatan Usahatani dan Pemasaran Kopi Arabika dan Robusta. Skripsi : Program Sarjana Manajemen Agribisnis. Fakultas Pertanian. Institut Pertanian Bogor. Bogor.

Soekartawi. 2011. Ilmu Usahatani. Universitas Indonesia : Jakarta.

Suratiyah, Ken. 2015. Ilmu Usahatani. Penebar Swadaya. Jakarta 